\title{
Gramática, cognição e sociedade: para uma gramática de significados, usos e variações*
}

\author{
Augusto Soares da Silva \\ Universidade Católica Portuguesa, Braga
}

\begin{abstract}
:
This study aims to highlight the relationship between grammar, cognition and society, identifying cognitive and social processes applied to grammatical constructions in Portuguese and their correlations. First, we will characterize certain cognitive operations that play an important role in grammar and that make it an efficient conceptual structuring and communication system: construal (our ability to view, conceive and portray the same situation in alternate ways); objectivity vs. subjectivity (the construal of a scene as detached or not from the conceptualizer); prominence (the focusing of attention on some aspects of a situation); mental spaces (packages of encyclopedic knowledge built and evoked in the current discourse); and inferences about the speaker's intended meanings. Then, we will show how these cognitive operations (which are common to language and other cognitive faculties, such as perception, attention, and memory) are configured and conditioned by sociocultural factors and communicative efficiency processes - hence the importance of intersubjectivity and cultural conceptualization, and the need for systematically including intralinguistic variation in grammar. The answer to the question of the correlation between cognitive processes and social processes in grammar is based on the cognitive science notion of social cognition and on multivariate and sociocognitive grammar models. A usage-based grammar implies a deconstruction of the linguistic system in favor of a view of language in its inevitable variability as a complex dynamic system and the construction of a multifactorial grammar model that may adequately unravel, through multivariate quantitative methods, the interplay between conceptual, structural and social factors. Finally, we will illustrate these principles of a grammar of meanings, uses and variations (in contrast with traditional perspective of a grammar of forms, structures and rules) with three studies on constructional variation in Portuguese. They are part of our sociocognitive and sociolectometrical research into convergence and divergence between European and Brazilian Portuguese: se constructions (reflexive, reciprocal, middle, anticausative, passive, impersonal) and the null se constructions; prepositional relative constructions and their chopping and resumptive counterparts; and the alternation between inflected and uninflected infinitival constructions.
\end{abstract}

Keywords: usage-based grammar, social cognition, meaning, constructional variation

Palavras-chave: gramática baseada no uso, cognição social, significado, variação construcional

\section{Introdução}

Epistemologicamente e em termos do pluralismo ontológico de Popper (1972), que estabelece a existência de três mundos, designadamente o mundo das entidades físicas, o mundo dos estados mentais individuais e o mundo dos produtos da mente humana, a linguagem, para além da sua realidade física, é também uma realidade psicológica que existe na mente dos falantes e uma realidade intersubjetiva que existe na comunidade como produto de ações dirigidas para outras finalidades. As teorias linguísticas tendem a privilegiar uma ou a outra destas duas últimas realidades linguísticas, de que Chomsky e Saussure são, respetivamente, exemplos paradigmáticos, sendo raras as vezes em que as dimensões psicológica e social da linguagem são simultânea e simetricamente consideradas. Defenderemos uma perspetiva maximamente integrada da correlação dos aspetos psicológicos e sociais da linguagem e exploraremos, com exemplos do português, as relações entre gramática,

*Este estudo foi financiado pela Fundação para a Ciência e a Tecnologia, como parte do Projeto PTDC/MHC-LIN/6915/2014. 
cognição e sociedade, seguindo o enquadramento teórico da Linguística Cognitiva (Geeraerts \& Cuyckens, 2007; Dancygier, 2017), especialmente os seus desenvolvimentos mais recentes que procuram responder não só ao "compromisso cognitivo" mas também ao "compromisso sociossemiótico" (Geeraerts, 2016), e das Ciências Cognitivas de segunda geração, que têm elaborado o conceito de cognição situada ou cognição social (Augoustinos, Walker \& Donaghue, 2006; Caldas, 2010; Fiske \& McCrae, 2012).

A questão central da investigação é, pois, saber como é que os processos cognitivos e as representações mentais dos falantes individuais têm impacto na realidade social da linguagem, como é que se dá a interface entre o nível mental e individual e o nível intersubjetivo e social da linguagem. A resposta podemo-la encontrar na natureza cognitiva da linguagem, (re)interpretando "linguagem como cognição", e no uso efetivo da linguagem, não na perspetiva sausurreana de um sistema internamente homogéneo, mas na inevitável variabilidade e heterogeneidade de uma comunidade linguística. Para o efeito, assumimos os seguintes pressupostos gerais: (1) a linguagem existe na mente individual, mas pertence à comunidade; (2) a linguagem é um meio de conhecimento partilhado e socialmente distribuído; (3) a linguagem é uma atividade intersubjetiva, histórica e socialmente variável; e (4) a linguagem é um sistema dinâmico complexo.

Tradicionalmente vista como um sistema puramente formal, a gramática de uma língua é plenamente significativa, tanto nas suas unidades como na construção de significados mais elaborados das expressões complexas, e reflete a experiência humana básica de perceção e ação sobre o mundo, donde ser a gramática uma parte integral da cognição e a base da interação verbal e da eficiência comunicativa. A gramática é um sistema de estruturação conceptual, que envolve capacidades cognitivas gerais (perceção, atenção, categorização, memória), conhecimentos sobre o mundo e processos cognitivos. A natureza prototipicamente abstrata dos significados gramaticais, em comparação com os significados lexicais, torna a gramática um poderoso e eficiente meio de construção, organização e, particularmente, perspetivação conceptual. As categorias gramaticais emergem do uso linguístico, isto é, são abstraídas e convenvionalizadas como rotinas cognitivas a partir da interação verbal, pelo que o objeto da gramática deve ser, não um sistema internamente homogéneo (como a langue de Saussure) nem um saber individual (como a competence de Chomsky), mas o uso efetivo, inevitavelmente variável.

Firmemente estabelecida no uso linguístico, a gramática é um sistema internamente heterogéneo e não uniformemente partilhado pelos membros da comunidade linguística, o que implica que a realidade psicológica e a realidade social da gramática não coincidem. Metodologicamente, a descrição gramatical tem de transcender o individual e centrar-se no interindividual, tem de ser fundamentalmente empírica, sem prescindir da introspeção, e tem de ser multifatorial para dar conta da complexidade e variabilidade dos fenómenos gramaticais. Fundamentado nestes princípios e explorando a interface dos processos cognitivos e sociais da gramática, com alguns exemplos de variações construcionais da gramática do português, o presente estudo pretende contribuir para uma gramática de significados, usos e variações, em oposição à perspetiva tradicional de uma gramática de formas, estruturas e regras.

Identificaremos primeiramente algumas das principais operações cognitivas que fazem da gramática um eficiente sistema de estruturação conceptual e de comunicação. Mostraremos, de seguida, o modo como essas operações cognitivas são configuradas e condicionadas por fatores socioculturais e por processos de eficiência comunicativa, donde a importância da intersubjetividade e da conceptualização cultural e a necessária inclusão sistemática da variação intralinguística na gramática. Responderemos ainda à questão da correlação entre processos cognitivos e processos sociais na gramática com base na noção de cognição social e em modelos gramaticais sociocognitivos e multivariados. Finalmente, ilustraremos os princípios cognitivos e sociais determinantes da gramática e suas correlações com três breves análises sobre variação construcional do português, que fazem parte do nosso estudo sociocognitivo e socioletométrico sobre convergência e divergência entre português europeu e brasileiro: construções de se (reflexiva, recíproca, média, anticausativa, passiva e impessoal) e a sua alternância com construções de clítico nulo, construções relativas preposicionais e as variantes cortadora e resuntiva e a alternância entre construções de infinitivo flexionado e não flexionado. 


\section{Processos cognitivos na gramática}

O significado de uma expressão linguística não se limita ao conteúdo conceptual que essa expressão designa; faz igualmente parte integrante desse significado o(s) modo(s) como esse conteúdo é construído. Quer isto dizer que a identidade semântica de uma expressão linguística inclui, não só um conteúdo conceptual, mas também o modo particular de construir/perspetivar esse conteúdo. Por exemplo, um copo com água a meio do seu volume pode ser conceptualizado de quatro perspetivas diferentes, cada uma das quais focaliza determinada faceta da situação: o recipiente em copo de água, o líquido em água no copo e, mais tipicamente, a parte com água em copo meio cheio e a parte sem água em copo meio vazio. Assim, a mesma situação da realidade é conceptualizada de modos diferentes e alternativos: cada expressão impõe uma perspetiva particular nessa situação e as quatro expressões são, pois, semanticamente bem distintas, apesar de terem as mesmas "condições de verdade". Este exemplo muito simples revela uma dimensão fundamental do significado linguístico e uma capacidade fundamental da cognição humana, que Langacker $(1987,1991,2008)$ designa como perspetivação conceptual ("construal"), isto é, a capacidade de conceptualizar e comunicar uma mesma situação de perspetivas alternativas. Esta é uma das principais operações cognitivas que determinam a estrutura e o uso de uma língua.

Os significados gramaticais revelam bem a importância cognitiva e semântica da perspetivação conceptual. Como o significado gramatical tende a ser abstrato, a sua função essencial é a de realizar o processo de perspetivação conceptual, razão pela qual a gramática é um dos mais poderosos e eficientes sistemas de organização e construção conceptual. A capacidade de perspetivação conceptual envolve um conjunto diversificado de operações de perspetivação conceptual - presentes não só na linguagem mas também noutras capacidades cognitivas gerais, como a visão e a atenção -, que têm sido linguisticamente exploradas e aplicadas a muitos e diversos fenómenos gramaticais principalmente por Langacker $(1987,1991,2008)$ e por Talmy (2000), por vezes utilizando diferentes terminologias para os mesmos processos cognitivos. Sem pretendermos fazer aqui um levantamento exaustivo nem uma sistematização das classificações existentes (ver, para isso, Verhagen, 2007 e Silva, 2008b), vamos apresentar sumariamente um conjunto de operações de perspetivação conceptual produtivas nas gramáticas das línguas.

Entendendo (metaforicamente) o processo de conceptualização em termos do processo de visão, a perspetiva constitui uma operação cognitiva fundamental, consistindo no arranjo de visão ("viewing arrangement") ou relação entre os "observadores" (conceptualizadores ou locutor-interlocutor) e situação "observada". Esta relação pode ser não marcada (padrão), quando locutor e interlocutor se situam conjuntamente numa localização fixa a partir da qual observam e descrevem ocorrências atuais no mundo que os envolve, ou mais frequentemente marcada, sempre que se configure qualquer desvio a este padrão de arranjo de visão. Um aspeto importante da perspetiva é o ponto de vista ou a posição estratégica. Este processo cognitivo está na base do contraste entre, por exemplo, as construções de movimento ir e comprar, de localização à frente e atrás e de transação vender e comprar.

Um outro aspeto da perspetiva, menos óbvio mas de igual importância, é a relação de objetividade vs. subjetividade (Langacker, 1987, 1991, 2008), isto é, a assimetria percetual entre o observador ou sujeito de perceção e a situação observada ou objeto de perceção. Uma situação é perspetivada com objetividade máxima quando é colocada "em palco", como foco explícito de atenção; pelo contrário, ela é perspetivada com subjetividade máxima quando permanece "fora de palco", inerente ao próprio processo de perceção, sem ser o alvo deste processo. Na construção objetiva o observador/conceptualizador não é envolvido na situação observada/conceptualizada, funcionando apenas como sujeito de conceptualização; a construção é subjetiva quando o observador/conceptualizador se envolve na situação a ponto de ser não só sujeito mas também objeto de conceptualização. A mudança da perspetivação objetiva para a perspetivação subjetiva constitui a operação conceptual de subjetificação e a mudança inversa constitui a operação conceptual de objetificação. Como exemplos de subjetificação na gramática do português, podemos apontar a construção $i r+I N F$ como marcador de futuro, a construção deixar + INF/QUE como expressão de causação negativa e o desenvolvimento de 
significados avaliativos e interacionais nas construções morfológicas com os sufixos diminutivo e aumentativo. Um exemplo de objetificação na gramática do português encontramo-lo na construção com infinitivo flexionado. Apresentaremos estes exemplos mais adiante, na secção 4.

Ainda um outro aspeto da perspetiva é o escaneamento mental de uma situação, isto é, a perceção de uma situação ora nas suas fases de desenvolvimento ora como um todo, a que corresponde, respetivamente o escaneamento sequencial e o escaneamento sumário. O tempo gramatical é uma das expressões mais produtivas de escaneamento sequencial. Consequentemente, na base da distinção ou alternância entre construção finita e construção não finita está o contraste cognitivo entre escaneamento sequencial e escaneamento sumário.

Um segundo tipo de operação de perspetivação conceptual é a proeminência ou saliência e consiste na (des)focalização de determinados elementos de uma situação. Uma expressão de proeminência reside no alinhamento assimétrico figura vs. fundo, bem conhecido da psicologia gestaltista, ou, na terminologia de Langacker (1987), trajetor vs. marco. Entre os participantes de uma situação, um é conceptualizado como figura ou participante primariamente focal que a expressão localiza ou caracteriza e outro é conceptualizado como fundo ou ponto de referência. A assimetria figura/fundo está na base, por exemplo, dos conceitos gramaticais de sujeito e objeto, bem como da transitividade e de qualquer construção preposicional. Uma outra organização assimétrica é o que Langacker (1987) designa como perfil vs. base e esta está presente em qualquer expressão linguística, já que qualquer expressão impõe um perfil numa base. O perfil é o que a expressão designa como entidade conceptual e a base é a estrutura conceptual que providencia o contexto essencial para a conceptualização da entidade perfilada. Retomando o exemplo do copo, meio cheio perfila o conteúdo do copo, ao passo que meio vazio perfila a porção por encher. Qualquer construção gramatical impõe um perfil na conceptualização de uma situação. Na base da oposição fundamental entre nome e verbo está a noção de perfil: os nomes perfilam entidades ou regiões num determinado domínio, ao passo que os verbos perfilam relações temporais entre entidades e todas as restantes categorias gramaticais perfilam relações não temporais. A voz gramatical é um outro exemplo prototípico do alinhamento perfil/base, sendo os contrastes entre construção ativa, passiva e média um exemplo eloquente de alteração desse alinhamento. Em sentido idêntico ao de perfil/base ou (des)focalização, Talmy (2000) fala da operação conceptual de abertura de janelas de atenção ("windowing").

Um terceiro tipo de operação de perspetivação conceptual consiste no facto de uma entidade ou situação poder ser conceptualizada em diferentes níveis de esquematicidade/especificidade. Por exemplo, podemos dizer que uma árvore que dá pinhões comestíveis é um pinheiro manso, um pinheiro ou, simplesmente, uma árvore. E escrever um artigo pode ser expresso como fazer algo. Ainda outro exemplo: a construção causativa analítica fazer alguém ver tem um significado mais esquemático do que a expressão causativa lexical mostrar. A operação de esquematização desempenha um papel importante no estabelecimento de categorias e construções gramaticais.

Um quarto tipo de operação de perspetivação conceptual é o que Talmy (2000) designa como dinâmica de forças e consiste na oposição entre uma entidade que exerce força, a entidade focal ou Agonista, e outra que exerce uma contraforça, o Antagonista. Para além desta dimensão da oposição de forças, o modelo de dinâmica de forças compreende ainda outras dimensões: a tendência intrínseca de força do Agonista ora para o movimento ou ação ora para o repouso ou inação; mudança ou início/cessação da contraforça vs. não mudança ou continuação/não ocorrência da contraforça; o resultado da interação de forças, ora ação ora inação do Agonista; e influência ('fazer') vs. não influência ('deixar') do Antagonista, donde o estado resultante do Agonista ser, respetivamente, oposto vs. igual ao da sua tendência intrínseca. O modelo cognitivo de dinâmica de forças tem inúmeras aplicações gramaticais: por exemplo, é a base conceptual das construções de causalidade, das construções de modalidade e da distinção entre o padrão acusativo e o padrão ergativo.

Já não propriamente uma operação de perspetivação conceptual, mas igualmente uma operação cognitiva de grande impacto gramatical é o que Fauconnier \& Turner (2002) designam como espaços mentais e o processo 
associado de integração conceptual. Aqueles são estruturas de conhecimento enciclopédico convocado on-line no discurso e associado às entidades e situações discursivamente referidas. Determinadas expressões linguísticas podem explicitamente introduzir espaços mentais, funcionando como construtores de espaços: por exemplo, gostaria, imagine, se, acho, expressões temporais, modais, conectores, adjetivos, etc. O processo de integração (ou mesclagem) conceptual consiste na fusão de dois ou mais espaços mentais de que emerge um espaço integrado ou espaço mescla, não subsumível à soma dos espaços input nem previsível a partir destes, mas uma nova conceptualização com uma dinâmica própria e uma estrutura conceptual emergente. A integração conceptual pode ser metafórica, como no exemplo abundantemente citado de "O cirurgião é um carniceiro", mas pode não o ser, como em "Se Beethoven fosse vivo, utilizaria um sintetizador”. A construção contrafactual cria um espaço novo que mescla o espaço musical atual e o espaço histórico de Beethoven como compositor inovador. O processo de integração conceptual é produtivo em muitos domínios gramaticais: entre outros, as construções condicionais, causativas, de movimento fictício, a oposição entre modo conjuntivo e modo indicativo, a referência indireta, opaca e ambígua.

As operações cognitivas anteriores são realizadas sobretudo pelo locutor, embora impliquem a necessária coordenação e a desejável cooperação locutor-interlocutor. Ora existem processos cognitivos primariamente realizados pelo interlocutor, igualmente fundamentais para o sucesso comunicativo. O principal contributo cognitivo do interlocutor é o processo de inferenciação. As inferências que o interlocutor é "convidado" a fazer acerca do significado de um enunciado são as chamadas implicaturas conversacionais (Grice, 1975). As implicaturas ativadas em atos de comunicação podem convencionalizar-se dando origem a novos significados e formas gramaticais ou a novas construções; é o que ocorre nos frequentes e produtivos processos diacrónicos de gramaticalização (Hopper \& Traugott, 2003) e construcionalização (Traugott \& Trousdale, 2013).

Serão universais estes processos cognitivos e gramaticais de perspetivação conceptual, de construção de espaços mentais e de integração conceptual e de inferenciação? A resposta é "sim e não". Estes processos são universais na medida em que envolvem capacidades cognitivas gerais do ser humano e também porque a constituição biológica e neurológica da espécie humana é a mesma independentemente da raça, da cor, da geografia ou da cultura. Mas as distinções que estes processos operam diferem de língua para língua, de cultura para cultura e ao longo do tempo, estando portanto inevitavelmente condicionados por fatores linguísticos, discursivos, sociais, culturais e históricos e, consequentemente, sujeitos às respetivas variações. Por outras palavras, estas operações mentais são biológica e neurologicamente universais, mas os seus "produtos", isto é, os significados, as gramáticas e as línguas são inevitavelmente diversas e variáveis.

\section{Processos sociais na gramática}

Os significados gramaticais, tal como os outros significados linguísticos, resultam, não apenas das operações cognitivas referidas na secção anterior, mas também de processos de convencionalização e sedimentação dos resultados dessas operações cognitivas, bem como de processos de eficiência comunicativa fundamentados em princípios pragmáticos e discursivos.

A linguagem é um sistema de uso governado por convenções e essas convenções podem manter-se ou ser alteradas, dando origem a mudanças e variantes que podem tornar-se novas convenções. Há assim processos de (i) manutenção das convenções, (ii) rutura e alteração das convenções e (iii) propagação das mudanças. E nestes processos atuam operações cognitivas, como as que vimos na secção anterior, e operações sociais. O modelo evolucionista da mudança linguística, desenvolvido por Croft (2000) e inspirado na teoria evolucionista neodarwiniana, em particular na teoria generalizada da seleção do biólogo e filósofo da ciência Hull (1988), mostra bem estes processos de estabilidade, inovação e propagação e os fatores cognitivos e sociais que estão na base dos respetivos processos linguísticos (ver em Silva, 2010b, 2014d uma discussão do modelo evolucionista de Croft). 
Estabilidade, inovação e propagação linguísticas processam-se no uso efetivo da língua, em atos efetivos de comunicação. A interação verbal pode ora preservar as convenções linguísticas ora romper as convenções e, seguidamente, convencionalizar as inovações. Tudo se processa no uso efetivo da língua, em eventos comunicacionais socialmente situados, com base em princípios de eficiência comunicativa. São naturalmente os processos de convencionalização ou propagação de variantes os que mais envolvem mecanismos sociais. No caso da mudança linguística, a seleção ou propagação das variantes pela comunidade linguística é feita através dos seguintes processos sociais: a acomodação às inovações linguísticas, o ato de identidade para o reconhecimento como membro do grupo e a adoção de mudanças, por prestígio, isto é, como forma de aspiração a um grupo social. Os falantes selecionam as variantes e replicam-nas nos seus atos de comunicação particulares com base nos valores sociais dessas variantes.

A nível do processo de aprendizagem de uma língua (materna, estrangeira ou segunda), os falantes aprendem o sistema linguístico por alinhamento mútuo uns com os outros, ora por imitação ora por adaptação, necessariamente a nível interacional. O alinhamento linguístico dos falantes é incompleto, na medida em que não é possível interagir com todos os falantes de uma língua, mas apenas com uma pequena parte. É assim que as interações comunicativas não só são eventos sociais como também refletem uma estrutura social, formada por grupos e redes sociais a que os falantes individuais pertencem e que configuram essas interações verbais.

Frequência e repetição (de "tokens" e de "types"), rotinização e outros fatores, como a saliência de conceitos, de referentes e de formas linguísticas, características dos falantes e aspetos sociais dos interlocutores e das situações de comunicação são determinantes quer no processo individual de sedimentação ("entrenchment") na mente dos falantes quer no processo coletivo de convencionalização na comunidade linguística das unidades e estruturas linguísticas (Bybee, 1985; Langacker, 1987; Tomasello, 2003; Schmid, 2015, 2017).

Sendo na interação verbal que as unidades e as estruturas linguísticas se estabelecem, se alteram, se sedimentam e se convencionalizam e sendo um dos principais resultados da evolução biológica do ser humano o sucesso comunicacional, um aspeto fundamental é a eficiência comunicativa, isto é, a maximização dos benefícios e a minimização dos custos comunicativos. Os benefícios comunicativos são os efeitos cognitivos que o locutor pretende produzir no interlocutor, como obter informação útil, satisfazer desejos, pedir tarefas, e os custos comunicativos são os esforços articulatórios e cognitivos implicados na produção linguística. $\mathrm{O}$ princípio de eficiência comunicativa tem sido objeto de vários estudos e sob diversas designações, entre os quais se destacam o princípio do menor esforço de Zipf (1965), as máximas conversacionais de Grice (1975) e de Keller (1994), o princípio de economia de Haiman (1983) e a teoria da relevância de Sperber \& Wilson (1986).

O princípio de eficiência comunicativa realiza-se mediante determinados princípios pragmáticos fundamentais. A comunicação é eficiente quando o locutor despende nem mais nem menos energia do que a necessária para produzir os pretendidos efeitos cognitivos no interlocutor. Quanto mais informativa, menos predizível, menos acessível e menos esperada é uma mensagem, maior é a mudança do estado cognitivo do interlocutor. $\mathrm{O}$ falante pode poupar esforços quando a informação que deseja transmitir já está disponível ou pode ser inferida a partir do contexto imediato, do conhecimento enciclopédico ou da experiência (Levinson, 2000).

Para além desta dimensão pragmática, o princípio de eficiência comunicativa tem também uma dimensão cognitiva. Assim, o locutor despenderá de menos esforço quando a informação é facilmente acessível ao interlocutor. Características da própria informação bem como fatores contextuais podem conferir a determinada informação maior ou menor acessibilidade mental (Ariel, 2001). Ainda uma outra dimensão da eficiência comunicativa é a probabilidade: determinados significados, determinadas formas ou determinadas construções podem ser mais prováveis do que outros. A probabilidade está inversamente correlacionada com a noção teórica de conteúdo informativo. 
O princípio de eficiência cognitiva, nas suas diferentes dimensões e manifestações, orienta a escolha entre variantes gramaticais, como, por exemplo, entre infinitivo flexionado e infinitivo não flexionado, presença ou ausência do clítico se em construções anticausativas e médias ou outras construções de se, construção causativa sintética (mostrar) e construção causativa analítica (fazer ver), construção causativa direta e construção causativa indireta, construção sintética do futuro e construção analítica com o auxiliar ir, etc. Por vezes, a informação é omitida porque simplesmente irrelevante. Um exemplo é a omissão do agente na construção passiva.

Outros processos sociais determinantes da gramática de uma língua são os fatores sociais da variação intralinguística, bem estudados pela Sociolinguística Variacionista de Labov (1972) e as normas semânticas para a distribuição e coordenação dos significados dentro da comunidade, designadamente as normas semânticas de cooperação, autoridade e conflito (Bartsch, 1987).

Identificados alguns dos principais processos cognitivos e alguns dos principais processos sociais determinantes da gramática de uma língua, cabe agora perguntar como interagem (e como correlacionar) ambos os processos na gramática. A resposta vamo-la encontrar nas ciências cognitivas de segunda geração e em modelos linguísticos sociocognitivos.

Tendemos a separar o individual e o coletivo, o pensamento e a ação e a considerar o pensamento individual interno preeminente à atividade supraindividual externa ou ao pensamento dirigido para a (inter)ação. A própria perspetiva cognitiva leva a estudar o objeto de estudo (memória, atenção, linguagem, comportamento ou outras capacidades cognitivas) de um ponto de vista psicológico, como parte da organização do conhecimento na mente individual, e a privilegiar assim a vertente individual e universal da cognição. Todavia, não podemos conceber cognição sem interação e esta ideia, já apontada na tradição fenomenológica de filósofos como Heidegger e Merleau-Ponty, ganha hoje evidências científicas graças aos recentes avanços das ciências cognitivas.

As ciências cognitivas de segunda geração, a partir dos anos 90, rompem com a conceção interna e autónoma da cognição, defendida pela geração anterior e sustentada no dualismo cartesiano mente-corpo e na ideia (metafórica) de que "a cognição é o cérebro", sendo assim um fenómeno individual e as funções mentais um epifenómeno das componentes físicas do cérebro. Vários autores de diversas ciências cognitivas, como a psicologia cognitiva, a biologia e a filosofia da mente (Varela, Thompson \& Rosch, 1991), a neurociência cognitiva (Edelman, 1992; Damásio, 1995, 2000) e a linguística cognitiva (Lakoff \& Johnson, 1999; Gibbs, 2006), convergem na hipótese da corporização ("embodiment”) ou mente/cognição corporizada, no sentido de que o sistema conceptual está integrado no corpo do indivíduo, em todos os seus aspetos, tanto os físicos como os funcionais e os sociais. Mais recentemente, tem sido explorada a situacionalidade ("situatedness") sociocultural da cognição e, assim, a interpretação da cognição como cognição situada ou cognição social, isto é, mentes individuais e processos cognitivos são configurados por interações sociais e culturais (Augoustinos, Walker \& Donaghue, 2006; Bernárdez, 2008; Frank, Dirven, Ziemke \& Bernárdez, 2008; Zlatev, Racine, Sinha \& Itkonen, 2008; Pishwa, 2009; Fiske \& Macrae, 2012). É também neste sentido que Wilson (2005) fala de mente coletiva, sugerindo que o nosso cérebro está especialmente preparado para estabelecer conexões com os outros cérebros, para comportamentos interativos e que a cognição é tão coletiva quanto individual, e que Caldas (2010) reúne evidências neurocientíficas sobre o cérebro social.

A cognição é situada, já que a atividade cognitiva tem sempre lugar num contexto sociocultural; a cognição é distribuída, pela repartição do esforço cognitivo entre dois ou mais indivíduos e entre eles e os seus instrumentos cognitivos; a cognição é sinérgica, como atividade de colaboração entre indivíduos, não só sincrónica, mas sobretudo sócio-histórica, cujos mecanismos são a imitação e os recentemente descobertos neurónios espelho. A perspetiva da cognição social faz, assim, a síntese do individual e do coletivo, do pensamento e da ação, do neuronal e do cultural, do cognitivo e do social, da mente e da comunidade. 
O reconhecimento da centralidade dos aspetos sociais e culturais da linguagem e a resposta ao "compromisso sociossemiótico" (Geeraerts, 2016) têm conduzido a Linguística Cognitiva, nos últimos dez ou quinze anos, a uma viragem social e a uma viragem empírica. Em linha com os desenvolvimentos das ciências cognitivas na compreensão da cognição social, a viragem social exprime-se em três níveis de análise. Um primeiro nível é o da variação intralinguística e está patente no desenvolvimento da Sociolinguística Cognitiva (Kristiansen \& Dirven, 2008; Geearerts, Kristiansen \& Peirsman, 2010; Pütz, Robinson \& Reif, 2012), uma extensão emergente da Linguística Cognitiva que investiga a interação entre fatores conceptuais e fatores sociais na variação linguística interna e se ocupa quer das diferentes formas de variação do significado quer do significado da variação ou representação mental da variação na mente dos falantes (ver uma introdução em Silva, 2009). Um segundo nível é o da variação interlinguística e está representada em comparações interculturais, antropológicas e históricas e, particularmente, na chamada Linguística Cultural (Palmer, 1996; Sharifian, 2011, 2015, 2017), que se ocupa sobretudo da expressão linguística da conceptualização cultural e dos modelos cognitivos culturais. Finalmente, o terceiro nível é o do próprio uso linguístico e está expresso nos estudos que integram no "compromisso cognitivo" a natureza socialmente interativa da comunicação linguística (Geeraerts, 2005; Zlatev, Racine, Sinha \& Itkonen, 2008; Croft, 2009; Harder, 2010).

Complementar da anterior, a viragem empírica é uma consequência inevitável da assunção do princípio de modelo da linguagem em uso e exprime-se na implementação de métodos empíricos e quantitativos avançados quer de corpus quer de experimentação e no desenvolvimento de um modelo de gramática multifatorial, capaz de determinar as correlações entre as variáveis conceptuais, socioculturais e discursivas (Geeraerts, 2006; Gries \& Stefanowitsch, 2006).

\section{Aplicações ao português: o projeto CONDIV}

Desenvolvemos o projeto CONDIV, uma investigação sociocognitiva e socioletométrica no contexto de línguas pluricêntricas (Clyne, 1992; Silva, 2014a) sobre convergência e divergência entre o português europeu (PE) e o português brasileiro (PB), pretendendo comprovar a tendência evolutiva divergente das duas variedades nacionais nos últimos 70 anos (Silva, 2010a, 2014b, c, 2015, 2016).

A primeira fase do projeto centrou-se na variação lexical (Silva, 2010a, 2014b, c). Os dados empíricos da investigação lexical foram coligidos a partir dos campos lexicais do futebol e do vestuário e incluem largos milhares de observações do uso de termos alternativos para nomear 43 conceitos nominais de futebol e de vestuário nos inícios das décadas de 50, 70 e 2000. Os materiais do corpus CONDIV, de cerca de 4 milhões de palavras (Silva, 2008c), foram extraídos de jornais de desporto e revistas de moda, linguagem da internete de chats associados a clubes de futebol e etiquetas de roupas de lojas de vestuário. Para medir convergência e divergência entre $\mathrm{PE}$ e $\mathrm{PB}$, foram utilizados métodos socioletométricos baseados em perfis onomasiológicos, sendo perfil onomasiológico o conjunto das expressões sinónimas alternativas usadas para designar determinado conceito ou função, juntamente com as suas frequências relativas. Por exemplo, os termos atacante, avançado, avante, dianteiro, forward e ponta de lança, juntamente com as suas frequências relativas no corpus, constituem o perfil onomasiológico do conceito de AVANÇADO. Os métodos socioletométricos incluem medidas de uniformidade, medidas do impacto de traços linguísticos e medidas de intenções atitudinais. Como método socioletométrico principal, a uniformidade ou medida da (dis)similaridade entre os perfis onomasiológicos nas diferentes variedades linguísticas consiste na soma das frequências relativas mais pequenas de cada expressão alternativa. Diacronicamente, convergência e divergência entre duas variedades traduzem-se em aumento ou diminuição da uniformidade ao longo do tempo, respetivamente. A análise socioletométrica dos dados lexicais permitiu concluir que a hipótese da divergência entre PE e PB se confirma no campo lexical do vestuário, mas não no do futebol. Os termos de vestuário são mais representativos do vocabulário comum e, por isso, os resultados do vestuário estarão mais próximos da realidade sociolinguística. 
A ligeira convergência no campo do futebol é um efeito da globalização e da estandardização do respetivo vocabulário. Outros resultados do mesmo estudo lexicológico mostram não haver nenhuma orientação de uma variedade em relação à outra, o que sugere um pluricentrismo simétrico entre $\mathrm{PE}$ e PB, e apontam para mais mudanças no PB do que no PE, maior influência estrangeira no PB do que no PE e maior distância entre estratos padrão e subpadrão no PB do que no PE.

A segunda fase do projeto CONDIV, em curso, ocupa-se da variação gramatical. Apresentamos a seguir sumários dos estudos sobre três tipos de construções alternativas em PE e PB: construções com o clítico se, construções relativas e construções infinitivas.

\subsection{Construções de se e a ausência do clítico}

O português, tal como outras línguas, possui uma rede polissémica de construções com o clítico se, designadamente as construções reflexiva, recíproca, média (pouco reconhecida nas gramáticas do português), anticausativa, passiva e impessoal, exemplificadas em (1)-(10). Estas construções distribuem-se num contínuo de transitividade que vai de eventos com dois participantes a eventos com um participante. Transitividade, distinguibilidade dos participantes e grau de controlo são os principais fatores que distinguem entre construções verdadeiramente reflexivas e construções médias: enquanto as primeiras envolvem maior distinguibilidade na conceptualização de facetas do participante e maior controlo por parte deste, as construções médias exprimem uma conceptualização indistinguível do participante e menor grau de controlo (Kemmer, 1993). Também designada como construção média-interna, a construção anticausativa caracteriza-se pela focalização da afetação do sujeito e desfocalização do agente e pela espontaneidade do evento como internamente motivado. Um outro contínuo construcional é o da atividade-agentividade e passividade: as construções de $s e$ impessoal e reflexivo/recíproco são claramente ativas e agentivas, ao passo que as restantes construções de $s e$ são médias e passivas. Em termos conceptuais, as construções de se evidenciam dois contínuos de perspetivação conceptual: um é o da maior proeminência da força indutora do evento e tem o seu grau maior na construção impessoal; o outro é o da maior proeminência do ponto terminal e tem os seus pontos mais elevados nas construções anticausativa, passiva e média.

(i) construção reflexiva/recíproca

(1) Então aí fica, ele, né, vai lá assim, de boa, e tal, e aí quando ela menstrua, e tá pronta pra casar, aí eles vão e se casam, né (C-Oral-Brasil)

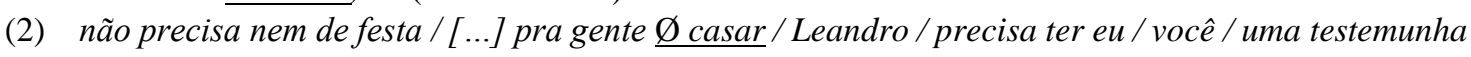
e o padre (C-Oral-Brasil)

(ii) construção média

(3) Mas, como é que foi, assim, que que cê se lembra desse processo, assim, conta. (C-Oral-Brasil)

(4) pq ela já Ølembra dos episódios que ela viu (Fóruns-Brasil)

(iii) construção anticausativa

(5) ...com uma idéia de valorizar a cultura popular que tava assim, aí já sofrendo um processo muito grande de, vindo muita gente de fora pra cá, e alguns dados tavam se perdendo. (C-Oral-Brasil)

(6) O arroz, Ø perdeu muito arroz na roça, porque a gente não podia trabalhar, né, Ø perdeu arroz. (Museu da Pessoa - Brasil)

(iv) construção passiva 
(7) o esforço é grande e nem sempre se colhem os frutos que se gostaria de colher (Museu da Pessoa Brasil)

(8) Uh, vai Ø inaugurar uma agência em Descalvado (Museu da Pessoa - Brasil)

(v) construção impessoal

(9) meu pai aprendeu a dirigir tarde, compra um carro usado e naquela época se usava testar os carros que você comprava usado. (Museu da Pessoa - Brasil)

(10) No meio Ø usa um verde cor cana (Fóruns - Brasil)

As construções de se têm uma alternativa em português formalmente caracterizada pelo apagamento do clítico e mais frequentemente usada no registo informal, como se exemplifica nos pares de (1)-(10), estando o clítico nulo marcado por $\emptyset$. As construções de se nulo são mais frequentes no PB do que no PE e é também no PB que o apagamento do clítico se observa na fala e na escrita de falantes de diferentes graus de escolaridade e de diferentes regiões e em todas as construções de se. O apagamento do clítico no PE é mais restringido, ocorrendo mais frequentemente nas construções anticausativas e somente com certos verbos de alternância anticausativa. As construções de se nulo no PB têm sido explicadas como resultado da tendência do PB para a perda morfológica dos clíticos. Ora, a razão fundamental é outra. Na verdade, a presença ou ausência do clítico se gera diferentes construções que exprimem diferentes conceptualizações do evento a que correspondem diferentes perspetivações conceptuais desse evento.

Comparemos os exemplos (11) e (12) com o verbo sentir e as instâncias repetidas do verbo lembrar em (13).

(11) Então ele pediu pa ir, trabalhar nas vilas e, favelas, e por aí afora, tá se sentindo mais à vontade (COral-Brasil)

(12) Ela Ø sente atraída por mulheres e já me confessou várias vezes que saiu com alguma amiga e elas se pegaram (Fóruns - Brasil)

(13) toda a vez que voce se lembrar dele, não Ø lembre dos momentos felizes juntos, isso não vai te ajudar em nada! se o foco é esquecer ele, então você deveria Ø lembrar só dos defeitos!! (Fóruns - Brasil)

O clítico se em (11) e na primeira ocorrência de (13) focaliza a mudança efetiva do estado emocional ou mental do experienciador - do fechamento para uma certa liberdade em (11) e do não querer lembrar para o não ser capaz de evitar lembrar em (12). O clítico restringe o escaneamento mental do evento à emergência inesperada ou ao momento da mudança. Além disso, põe em perfil a energia do experienciador para levar a cabo a mudança, induzindo assim uma dinâmica de forças no participante principal que age como agente e como paciente da mudança e, consequentemente, diminui o seu controlo na própria atividade emocional ou mental. Ao realizar estas funções, o clítico se introduz a perspetiva do locutor/conceptualizador. Pelo contrário, o apagamento do clítico em (12) e (13) desfocaliza a mudança efetiva para estender o escaneamento mental do evento e dar conta do processo de mudança como um todo - sentir atração por mulheres em (12) e lembrar, não os momentos felizes, mas os defeitos dele em (13). O clítico nulo desfocaliza a energia do experienciador e a dinâmica de forças subsequente para permitir que a mudança de estado emocional (sentir atração por mulheres) ou de estado mental (lembrar apenas os defeitos dele) seja conceptualizada como autónoma e focalizada no ponto terminal da mudança. O experienciador em (12) e na segunda metade de (13) é conceptualizado como tendo suficiente controlo para sentir atração por mulheres e para lembrar apenas os defeitos dele.

Os exemplos (11)-(13) ilustram bem as diferenças de perspetivação conceptual do evento entre a presença e a ausência do clítico. O clítico explícito em (11) e na primeira ocorrência de (13) codifica uma 
conceptualização energética e de dinâmica de forças da situação, atenuando o controlo ou a proeminência do participante principal e focalizando a mudança efetiva e inesperada deste bem como a sua afetação. Quer isto dizer que o clítico se exprime uma perspetivação subjetiva da situação, na medida em que leva a que o locutor se envolva na conceptualização do evento. Em contrapartida, o clítico nulo em (12) e (13) codifica uma conceptualização absoluta da situação, um processo temático concebido autonomamente, sem invocar a energia que o induz. Por outras palavras, o apagamento do clítico exprime uma perspetivação objetiva da situação, como que desconectada do locutor.

Propomos assim que o apagamento do clítico se serve para exprimir uma conceptualização autónoma do evento de dois modos. Uma via é enfatizar, no ponto terminal, a passividade e a afetação do indutor de energia ou do tema e a autonomia do processo temático. É o que acontece com o clítico nulo médio, anticausativo, passivo e reflexivo/recíproco. A outra via é enfatizar, no ponto terminal, a impessoalidade da fonte de energia e do processo agentivo. É o que sucede com o clítico nulo impessoal.

\subsection{Construções relativas preposicionais e as estratégias cortadora e resuntiva}

Os exemplos (14)-(16) ilustram a alternância entre três construções relativas preposicionais: construção padrão (14), construção cortadora (15) e construção resuntiva (16).

(14) Ô Ney, o homem é produto do meio em que vive. (NURC-RJ)
a. [...] porque há uma canção que eu gosto muito. (C-Oral-Portugal)
b. O primeiro restaurante que comemos foi horrível. (PB, Google)
c. Dieta que morre de fome não rola. (PB, Google)

(16) [devido] a umas algas que agora esquece-me o nome delas. (PE, CRPC)

Os estudos existentes sobre esta variação limitam-se a assinalar as diferenças estilísticas (as construções cortadora e resuntiva são mais próprias do registo informal, sendo a construção padrão típica do registo formal) e dialetais (a construção cortadora é mais frequente no PB do que no PE), ou descrevem-na em termos formais, como resultado de regras de movimento ("wh-movement") e de elevação ("raising"). Ora, a alternância entre estas três construções é determinada sobretudo por fatores cognitivos e sociais.

A despronominalização do pronome relativo e a sua gramaticalização como complementador facilitam as estratégias cortadora e resuntiva e abrem caminho a relações semânticas e pragmáticas mais flexíveis entre o antecedente nominal e a oração relativa. A construção relativa envolve uma relação de ponto de referência entre um nome/tópico e uma proposição, sendo esta interpretada com base no quadro conceptual daquele. Assim, a interpretação da relativa cortadora depende da capacidade de atribuir um papel semântico único ao antecedente nominal dentro do seu quadro conceptual e em relação semântica com o predicado relativo. Isto acontece quer nos casos em que o antecedente nominal é complemento do verbo da oração relativa, como no exemplo (15a), ou adjunto, como em (15b), quer quando não há qualquer relação sintática entre antecedente nominal e predicado da oração, como no exemplo (15c). Neste último caso (15c), a construção relativa emerge do processo de integração conceptual de elementos dos dois espaços mentais - o do antecedente nominal e o do verbo da oração relativa. Quanto à construção resuntiva, esta estratégia não canónica é possibilitada pelo princípio cognitivo e comunicativo de acessibilidade do referente. Além disso, quanto maior for o grau de sedimentação cognitiva da relação de ponto de referência entre antecedente nominal e verbo da oração relativa, maior é a probabilidade das estratégias relativas resuntiva e cortadora. 


\title{
4.3. Construções infinitivas e o infinitivo flexionado
}

Comparemos a construção de infinitivo flexionado ( $\mathrm{Inf} \mathrm{Fl}$ ) com a construção alternativa de infinitivo não flexionado (Inf NFl) da construção completiva de (17) e da construção adverbial de (18). A construção com Inf Fl $(17 b, 18 b)$ exprime maior independência, maior especificidade, maior proeminência, maior distância conceptual e major objetividade do evento subordinado relativamente ao evento principal, do que a construção com Inf NFl (17a, 18a).

\author{
a. É preciso fazer uma pausa. \\ b. É preciso fazermos uma pausa. \\ a. Alegram-se por ver o pai. \\ b. Alegram-se por verem o pai.
}

A flexão - por si própria ou conjuntamente com o sujeito explícito - torna o sujeito do infinitivo mais proeminente no contexto da conceptualização do evento, já que fornece informação acerca desse participante. A flexão "põe em palco" o participante principal como foco específico de atenção, como objeto de per/conceção. A flexão de pessoa tende a aumentar a distância entre o evento subordinado e o conceptualizador, fazendo com que o evento ganhe uma certa independência e possa ser visto a partir do "exterior". Deste modo, a flexão de pessoa aumenta a assimetria entre observador e observado e, consequentemente, cria as condições para uma conceptualização objetiva. A menção explícita de uma entidade ou situação e a maior distância conceptual em relação ao conceptualizador têm um efeito objetificador. A construção com Inf Fl codifica assim uma objetificação na conceção do sujeito do infinitivo (ver Silva, 2008a para mais desenvolvimento).

Três grupos de fatores podem favorecer a construção com Inf Fl: (i) a autonomia sintático-semântica da oração infinitiva, (ii) a verbalidade do infinitivo e o consequente estatuto oracional da construção infinitiva e (iii) a acessibilidade mental do sujeito do infinitivo (Silva, 2008; ; Vesterinen, 2011; Vanderschueren, 2013). Relativamente à autonomia sintático-semântica, a construção bioracional é favorável à ocorrência de Inf Fl. Quanto ao segundo fator, há uma correlação positiva entre a verbalidade do infinitivo e a ocorrência do Inf Fl. Assim, a forma pronominal do verbo no infinitivo, a presença de reflexivos, a construção passiva, a construção perifrástica, a presença de predicativos e a negação do infinitivo favorecem a ocorrência do Inf Fl. Por outro lado, e como efeito de compensação, o Inf Fl ocorre mais frequentemente com verbos não dinâmicos do que com verbos dinâmicos. Finalmente, quanto ao terceiro fator, a anteposição e a interposição do infinitivo, a pausa e uma maior distância entre infinitivo e antecedente do sujeito do infinitivo dificultam a acessibilidade do sujeito do infinitivo e, consequentemente, favorecem a construção com Inf Fl. Desenvolvendo uma rigorosa análise multifatorial de corpus, Vanderschueren (2013) mostra que, nas construções infinitivas adverbiais, a autonomia e a verbalidade do infinitivo têm um impacto maior na opção pela construção de Inf Fl do que a acessibilidade do sujeito do infinitivo.

\section{Conclusão}

Três tipos de operações cognitivas estão na base da estrutura e do uso da linguagem e da gramática: a perspetivação conceptual permitindo conceptualizar determinada situação de modos alternativos, a construção de espaços mentais no discurso e a realização de inferências. Pela sua natureza mais abstrata, os significados gramaticais potenciam as diversas operações de perspetivação conceptual: a perspetiva ou arranjo de visão entre locutor e interlocutor, o ponto de vista, objetividade vs. subjetividade determinando até que ponto o conceptualizador toma parte da situação descrita, o escaneamento sequencial ou holístico do desenvolvimento temporal de uma situação, a proeminência de determinados elementos da situação e os alinhamentos 
assimétricos figura vs. fundo e perfil vs. base, o nível de especificidade/esquematicidade na conceptualização de uma situação e a dinâmica de forças entre os protagonistas de uma situação. Qualquer situação descrita no discurso evoca espaços mentais, havendo expressões que servem para abrir esses espaços, e diferentes espaços mentais podem integrar-se em espaços mesclados fazendo emergir novos significados e novas construções. Ao interlocutor cabe realizar inferências ou implicaturas conversacionais a partir do que é dito pelo locutor e acerca dos significados pretendidos por este. Perspetivação conceptual, construção discursiva de espaços mentais e inferenciação são operações cognitivas universais, na medida em que se baseiam em capacidades cognitivas gerais do ser humano, mas os produtos destas operações diferem cultural, histórica e linguisticamente.

Os significados e as construções gramaticais resultam também de processos de convencionalização e de estratégias de eficiência comunicativa fundamentadas em princípios pragmáticos e discursivos. A interação verbal ora preserva as convenções linguísticas ora as rompe e convencionaliza inovações linguísticas. A difusão das variantes faz-se por imitação ou adaptação, por acomodação, identidade ou prestígio. A interação verbal orienta-se pelo princípio de eficiência comunicativa e este princípio, que maximiza os benefícios e minimiza os custos comunicativos, orienta a escolha entre variantes gramaticais. A necessária integração dos fatores cognitivos e dos fatores sociais da linguagem e da gramática explica-se através da reinterpretação da cognição como atividade distribuída e socioculturalmente situada, como cognição social, e realiza-se através de determinados modelos como a sociolinguística cognitiva ou outras sínteses sociocognitivas e através de métodos empíricos multivariacionais.

Ilustrámos estes processos cognitivos e sociais com três exemplos de variação construcional da gramática do português nas variedades nacionais do PE e PB. Um exemplo é o apagamento do clítico se, frequente no PB em todas as construções de $s e$ - reflexiva, recíproca, média, anticausativa, passiva e impessoal -, codificando uma conceptualização autónoma e objetiva do evento, em contraste com a perspetivação energética e subjetiva do evento marcada pela presença do clítico se. O segundo exemplo é a alternância entre a construção relativa preposicional e as construções relativas cortadora e resuntiva: as construções não canónicas cortadora e ressuntiva, ambas presentes nas duas variedades, sendo a cortadora mais frequente no PB do que no PE, são facilitadas pelos processos cognitivos e comunicativos de integração conceptual de espaços mentais e de acessibilidade mental do referente, respetivamente. O terceiro e último exemplo é o da variação entre infinitivo flexionado e infinitivo não flexionado: a construção de infinitivo flexionado codifica uma objetificação na conceptualização do sujeito do infinitivo e é favorecida quando a oração de infinitivo apresenta maior autonomia e quando o infinitivo possui características de maior verbalidade.

Pretendemos assim contribuir para uma gramática simultaneamente cognitiva e social do português, que integre e correlacione os processos cognitivos e os processos sociais que determinam a língua portuguesa. Pretendemos também contribuir para uma gramática pluricêntrica do português, que dê conta das diferenças entre as variedades nacionais do português e reconheça e promova o português como língua pluricêntrica (apesar do boom gramatical nos últimos quinze anos tanto no Brasil como em Portugal, as gramáticas que temos são monocêntricas). Pretendemos, enfim, contribuir para o desenvolvimento de uma gramática de significados, usos e variações do português.

\section{Referências}

Ariel, Mira (2001) Accessibility theory: An overview. In Sanders, Ted; Schliperoord, Joost \& Spooren, Wilbert (eds.), Text Representation, Amsterdam/Philadelphia: John Benjamins, pp. 29-87.

Augoustinos, Martha; Walker, Iain \& Donaghue, Ngaire (2006) Social Cognition: An Integrated Introduction. London: Sage.

Bartsch, Renate (1987) Norms of Language. Theoretical and practical aspects. London/New York: Longman. 
Bernárdez, Enrique (2008) El Lenguaje como Cultura. Una crítica del discurso sobre el lenguaje. Madrid: Alianza Editorial.

Bybee, Joan L. (1985) Morphology: A study of the relation between meaning and form. Amsterdam/Philadelphia: John Benjamins.

Caldas, Alexandre Castro (2010) The social brain. In Silva, Augusto Soares da et al. (eds.), Comunicação, Cognição e Media. Vol. 1. Braga: Publicações da Faculdade de Filosofia da Universidade Católica Portuguesa, pp. 33-40.

Clyne, Michael (ed.) (1992) Pluricentric Languages. Differing norms in different nations. Berlin/New York: Mouton de Gruyter.

Croft, William (2000) Explaining Language Change: An Evolutionary Approach. London: Longman.

Croft, William (2009) Towards a social Cognitive Linguistics. In Evans, Vyvyan \& Pourcel, Stéphanie (eds.), New Directions in Cognitive Linguistics. Amsterdam/Philadelphia: John Benjamins, pp. 395-420.

Damásio, António (1995) O Erro de Descartes. Emoção, razão e cérebro humano. Lisboa: Publicações EuropaAmérica.

Damásio, António (2000) O Sentimento de Si. O corpo, a emoção e a neurobiologia da consciência. Lisboa: Publicações Europa-América.

Dancygier, Barbara (ed.) (2017) The Cambridge Handbook of Cognitive Linguistics. Cambridge: Cambridge University Press.

Edelman, Gerald M. (1992) Bright Air, Brilliant Fire: On the Matter of the Mind. New York: Basic Books.

Fauconnier, Gilles \& Turner, Mark (2002) The Way We Think: Conceptual Blending and the Mind's Hidden Complexities. New York: Basic Books.

Fiske, Susan \& McCrae, Neil (eds.) (2012) The Sage Handbook of Social Cognition. London: Sage.

Frank, Roslyn M.; Dirven, René; Ziemke, Tom \& Bernárdez, Enrique (eds.) (2008) Body, Language, and Mind. Volume 2. Sociocultural Situatedness. Berlin/New York: Mouton de Gruyter.

Geeraerts, Dirk. (2005) Lectal variation and empirical data in cognitive linguistics. In Ruiz de Mendoza, Francisco \& Peña Cervel, Sandra (eds.), Cognitive Linguistics. Internal dynamics and interdisciplinary interactions. Berlin/New York: Mouton de Gruyter, pp. 163-189.

Geeraerts, Dirk (2006) Methodology in Cognitive Linguistics. In Kristiansen, Gitte; Achard, Michel; Dirven, René \& Ruiz de Mendoza, Francisco (eds.), Cognitive Linguistics. Current applications and future perspectives. Berlin/New York: Mouton De Gruyter, pp. 21-49.

Geeraerts, Dirk (2016) The sociosemiotic commitment. Cognitive Linguistics 27(4), pp. 527-542.

Geeraerts, Dirk \& Cuyckens, Hubert (eds.) (2007) The Oxford Handbook of Cognitive Linguistics. Oxford/New York: Oxford University Press.

Geeraerts, Dirk, Kristiansen, Gitte \& Peirsman, Yves (eds.) (2010) Advances in Cognitive Sociolinguistics. Berlin/New York: Mouton de Gruyter.

Gibbs, Raymond W. (2006) Embodiment and Cognitive Science. Cambridge: Cambridge University Press.

Grice, H. Paul (1975) Logic and conversation. In Cole, Peter \& Morgan, Jerry (eds.), Syntax and Semantics, vol. 3, Speech Acts. New York: Academic Press, pp. 41-58.

Gries, Stefan Th. \& Stefanowitsch, Anatol (eds.) (2006) Corpora in Cognitive Linguistics. Corpus-based approaches to syntax and lexis. Berlin/New York: Mouton de Gruyter.

Haiman, John (1985) Natural syntax: Iconicity and erosion. Cambridge: Cambridge University Press.

Harder, Peter (2010) Meaning in Mind and Society. A functional contribution to the social turn in Cognitive Linguistics. Berlin/New York: Mouton de Gruyter.

Hopper, Paul J. \& Traugott, Elizabeth C. (2003) Grammaticalization. Cambridge: Cambridge University Press.

Hull, David L. (1988) Science as a Process: An evolutionary account of the social and conceptual development of science. Chicago: University of Chicago Press. 
Keller, Rudi (1994) On Language Change: The invisible hand in language. London/New York: Routledge.

Kristiansen, Gitte \& Dirven, René (eds.) (2008) Cognitive Sociolinguistics: Language variation, cultural models, social systems. Berlin/New York: Mouton de Gruyter.

Labov, William (1972) Sociolinguistic Patterns. Philadelphia: University of Pennsylvania Press.

Lakoff, George \& Johnson, Mark (1999) Philosophy in the Flesh: The embodied mind and its challenge to Western thought. New York: Basic Books.

Langacker, Ronald W. (1987) Foundations of Cognitive Grammar, Vol. 1: Theoretical Prerequisites. Stanford: Stanford University Press.

Langacker, Ronald W. (1991) Foundations of Cognitive Grammar, Vol. 2: Descriptive Application. Stanford: Stanford University Press.

Langacker, Ronald W. (2008) Cognitive Grammar. A basic introduction. Oxford: Oxford University Press.

Levinson, Stephen C. (2000) Presumptive Meanings: The theory of generalized conversational implicature. Cambridge, MA: MIT Press.

Pishwa, Hanna (ed.) (2009) Language and Social Cognition. Expression of the social mind. Berlin/New York: Mouton de Gruyter.

Palmer, Gary B. (1996) Toward a Theory of Cultural Linguistics. Austin: University of Texas Press.

Popper, Karl (1972) Objective Knowledge: An evolutionary approach. Oxford: Clarendon Press.

Pütz, Martin; Robinson, Justyna A. \& Reif, Monika (eds.) (2012) Cognitive Sociolinguistics: Social and cultural variation in cognition and language use. Amsterdam/Philadelphia: John Benjamins.

Schmid, Hans-Jörg (2015) A blueprint of the entrenchment-and-conventionalization model. Yearbook of the German Cognitive Linguistics Association 3, pp. 1-27.

Schmid, Hans-Jörg (2017) A framework for understanding linguistic entrenchment and its psychological foundations. In Schmid, Hans-Jörg (ed.), Entrenchment and the Psychology of Language Learning, Berlin/Boston: Mouton de Gruyter, pp. 9-35.

Sharifian, Farzad (2011) Cultural Conceptualizations and Language: Theoretical framework and applications. Amsterdam/Philadelphia: John Benjamins.

Sharifian, Farzad (2015) Cultural Linguistics. In Sharifian, Farzad (ed.), The Routledge Handbook of Language and Culture, London: Routledge, pp. 473-492.

Sharifian, Farzad (2017) Advances in Cultural Linguistics. Singapore: Springer.

Silva, Augusto Soares da (2008a) The Portuguese inflected infinitive and its conceptual basis. In LewandowskaTomaszczyk, Barbara (ed.), Asymmetric Events. Amsterdam/Philadelphia: John Benjamins, pp. 225-241.

Silva, Augusto Soares da (2008b) Perspectivação conceptual e gramática. Revista Portuguesa de Humanidades - Estudos Linguísticos 12(1), pp. 17-44.

Silva, Augusto Soares da (2008c) O corpus CONDIV e o estudo da convergência e divergência entre variedades do português. In Costa, Luís; Santos, Diana \& Cardoso, Nuno (eds.), Perspectivas sobre a Linguateca/Actas do Encontro Linguateca: 10 anos. Linguateca, pp. 25-28.

Silva, Augusto Soares da (2009) A Sociolinguística Cognitiva: razões e objecto de uma nova área de investigação linguística. Revista Portuguesa de Humanidades - Estudos Linguísticos 13(1), pp. 191-212.

Silva, Augusto Soares da (2010a). Measuring and parameterizing lexical convergence and divergence between European and Brazilian Portuguese. In Geeraerts, Dirk; Kristiansen, Gitte \& Peirsman, Yves (eds.), Advances in Cognitive Sociolinguistics. Berlin/New York: Mouton de Gruyter, pp. 41-83.

Silva, Augusto Soares da (2010b) Replication, selection and language change. Why an evolutionary approach to language variation and change? Revista Portuguesa de Filosofia 66(4), pp. 803-818.

Silva, Augusto Soares da (ed.) (2014a) Pluricentricity: Language variation and sociocognitive dimensions. Berlin/Boston: Mouton de Gruyter. 
Silva, Augusto Soares da (2014b) The pluricentricity of Portuguese: A sociolectometrical approach to divergence between European and Brazilian Portuguese. In Silva, Augusto Soares da (ed.), Pluricentricity. Language variation and sociocognitive dimensions. Berlin/Boston: Mouton de Gruyter, pp. 143-188.

Silva, Augusto Soares da (2014c) Measuring and comparing the use and success of loanwords in Portugal and Brazil: A corpus-based and concept-based sociolectometrical approach. In Zenner, Eline \& Kristiansen, Gitte (eds.), New Perspectives on Lexical Borrowing: Onomasiological, methodological and phraseological innovations. Berlin/Boston: Mouton de Gruyter, pp. 101-141.

Silva, Augusto Soares da (2014d) Evolucionismo, integración sociocognitiva y cambio semântico. Caplletra. Revista Internacional de Filologia 56, pp. 137-156.

Silva, Augusto Soares da (2015) Cultural cognitive models of language variation. Romanticism and rationalism in language policy debates about the unity/diversity of European and Brazilian Portuguese. In Daems, Jocelyne et al. (eds.), Change of Paradigms - New Paradoxes. Recontextualizing Language and Linguistics. Berlin/Boston: Mouton de Gruyter, pp. 253-274.

Silva, Augusto Soares da (2016) The cognitive approach to pluricentric languages and the pluricentricity of Portuguese: What's really new? In Muhr, Rudolf (ed.), Pluricentric Languages and Non-Dominant Varieties Worldwide. II: The Pluricentricity of Portuguese and Spanish. Wien: Peter Lang, pp. 13-34.

Sperber, Dan \& Wilson, Deirdre (1986) Relevance: Communication and Cognition. Oxford: Blackwell Publishers.

Talmy, Leonard (2000) Toward a Cognitive Semantics. Vol. I: Concept Structuring Systems. Vol. II: Typology and Process in Concept Structuring. Cambridge, MA: The MIT Press.

Tomasello, Michael (2003) Constructing a Language: A usage-based theory of language acquisition. Cambridge, MA: Harvard University Press.

Traugott, Elizabeth C. \& Trousdale, Graeme (2013) Constructionalization and Constructional Changes. Oxford: Oxford University Press.

Vanderschueren, Clara (2013) Infinitivo y Sujeto en Portugués y Español. Un estudio empírico de los infinitivos adverbiales con sujeto explícito. Berlin/New York: Mouton de Gruyter.

Varela, Francisco; Thompson, Evan \& Rosch, Eleanor (1991) The Embodied Mind. Cambridge, MA: MIT Press.

Verhagen, Arie (2007) Construal and perspectivization. In Geeraerts, Dirk \& Cuyckens, Hubert (eds.), The Oxford Handbook of Cognitive Linguistics. Oxford: Oxford University Press, pp. 48-81.

Vesterinen, Rainer (2011) A Cognitive Approach to Adverbial Subordination in European Portuguese. The infinitive, the clitic pronoun se and finite verb forms. Cambridge: Cambridge Scholars Publishing.

Wilson, Robert A. (2005) Boundaries of the Mind. The individual in the fragile sciences. Cambridge: Cambridge University Press.

Zipf, George K. (1965) The Psychobiology of Language: An introduction to dynamic Philology. Cambridge, MA: MIT Press.

Zlatev, Jordan; Racine, Timothy P.; Sinha, Chris \& Itkonen, Esa (eds.) (2008) The Shared Mind: Perspectives on intersubjectivity. Amsterdam/Philadelphia: John Benjamins. 